\title{
Aplikasi Algoritma Greedy Terhadap Permasalahan Integer Knapsack pada Toko Surya Muda Pekanbaru
}

\author{
Sri Basriati ${ }^{1}$, Elfira Safitri, ${ }^{2}$, Meli Ermanita ${ }^{3}$ \\ 1,2,3 Jurusan Matematika, Fakultas Sains dan Teknologi, UIN Sultan Syarif Kasim Riau \\ Jl. HR. Soebrantas No. 155 Simpang Baru, Panam, Pekanbaru, 28293 \\ Email: sribasriati@uin-suska.ac.id, meliermanita20@gmail.com
}

\begin{abstract}
ABSTRAK
Permasalahan integer knapsack merupakan permasalahan pengangkutan atau pemilihan barang yang akan dimasukan secara keseluruhan atau tidak sama sekali dalam satu item sehingga tidak melebihi kapasitas dari pengangkut atau wadah. Algoritma greedy dalah metode yang digunakan untuk menyelesaikan permasalahan optimasi. Pada penelitian ini, algoritma greedy digunakan untuk memilih barang yang akan diangkut oleh Toko Surya Muda Pekanbaru agar mendapatkan keuntungan yang maksimum. Berdasarkan perhitungan dari ketiga strategi dari algoritma greedy yaitu greedy by profit, greedy by weight dan greedy by density didapatkan bahwa strategi greedy by density menghasilkan solusi yang lebih optimal dari pada greedy by profit dan greedy by weight.
\end{abstract}

Kata Kunci: Algoritma greedy, integer knapsack, pengangkutan barang

\begin{abstract}
The integer knapsack problem is a problem of transportation or selection of goods that will be included in whole or not in one item so that it does not exceed the capacity of the carrier or container. Greedy algorithm is a method used to solve optimization problems. In this study, the greedy algorithm is used to select goods to be transported by the Surya Muda Pekanbaru Shop in order to get the maximum profit. Based on the calculation of the three strategies of the greedy algorithm, namely greedy by profit, greedy by weight and greedy by density, it is found that the greedy by density strategy produces a solution that is more optimal than greedy by profit and greedy by weight.
\end{abstract}

Keywords: Greedy algorithm, integer knapsack, transportation of goods.

\section{Pendahuluan}

Permasalahan optimasi adalah permasalahan dalam pemilihan barang-barang yang akan dimasukkan ke dalam sebuah pengangkut atau wadah yang digunakan untuk mengangkut barang-barang yang akan dibeli untuk dijual kembali. Tujuan dari pemilihan barang yang akan diangkut adalah untuk memperoleh keuntungan yang maksimal. Penentuan pemilihan barang dalam permasalahan optimasi termasuk ke dalam permasalahan knapsack. Salah satu metode yang digunakan untuk menentukan pemilihan barang dalam permasalahan knapsack adalah integer knapsack. Permasalahan integer knapsack (knapsack 0-1) merupakan permasalahan pengangkutan barang, dimana barang akan dimasukkan secara keseluruhan atau tidak sama sekali dalam satu item, Paryati [4].

Menurut Zulhidayati [7], algoritma greedy adalah salah satu metode yang paling sering digunakan dalam menyelesaikan permasalahan knapsack. Algoritma greedy memecahkan masalah langkah per langkah. Setiap langkah merupakan pilihan untuk membuat langkah optimum lokal dengan harapan bahwa angkah sisanya mengarah ke solusi optimum global. Algoritma greedy memiliki perbedaan dengan algoritma lainnya diantaranya yaitu dari segi kecepatan dan segi ketepatan. Perhitungan algoritma greedy yang menggunakan komputasi akan lebih cepat dikarenakan algoritma greedy menggunakan prinsip pemilihan keputusan disetiap langkahnya. Algoritma greedy tidak beroperasi secara menyeluruh terhadap semua alternatif solusi yang ada sehingga algoritma greedy tidak selalu memberikan hasil yang optimal, akan tetapi memberikan hasil optimal ketika terdapat banyak alternatif yang diberikan seperti yang dikemukakan oleh Hasan [3].

Penelitian tentang masalah knapsack telah dilakukan oleh beberapa peneliti, diantaranya penelitian masalah knapsack oleh Setemen [6] dengan studi kasus pemilihan buah kemasan kotak dengan 
menggunakan algoritma genetik dan memberikan hasil yang optimal. Selanjutnya Pratiwi [5] mengemukakan bahwa dalam pengoptimalan muatan barang dengan menggunakan algoritma branch and bound yang memberikan keuntungan penjualan maksimal. Menurut Ambarwari [1] pula, penerapan algoritma greedy pada permasalahan knapsack untuk optimasi pengangkutan peti kemas yang memberikan kesimpulan bahwa algoritma greedy memberikan keuntungan yang besar pada pemilihan peti kemas. Berdasarkan latar belakang tersebut penulis tertarik untuk mengulas kembali permasalahan integer knapsack dengan menggunakan algoritma greedy kemudian mengaplikasikannya di salah satu toko di Kota Pekanbaru.

\section{Permasalahan Knapsack}

\section{Metode Penelitian}

Knapsack diartikan sebagai sebuah tas atau wadah, permasalahan knapsack merupakan permasalahan tentang pemilihan barang dari sejumlah barang yang memiliki bobot atau nilai yang berbeda-beda, sehingga diperoleh keuntungan yang maksimal tanpa melebihi kapasitas dari tas atau wadah yang tersedia.

Bentuk umum dari permasalahan integer knapsack adalah sebagai berikut:

Maksimun $Z=\sum_{i=1}^{n} p_{i} x_{i}$

dengan kendala:

Keterangan:

$$
\sum_{i=1}^{n} w_{i} x_{i} \leq M, x_{i} \in\{0,1\}
$$

Z: Nilai optimum dari nilai fungsi tujuan

$n$ : Banyak barang

$p_{i}$ : Keuntungan barang ke- $i$ keseluruhan dimana $i=1,2,3, \ldots, n$

$w_{i}$ : Berat barang ke- $i$ keseluruhan, dimana $i=1,2,3, \ldots, n$

$x_{i}$ : Variabel keputusan (1 jika dipilih, 0 jika tidak dipilih)

$M:$ Kapasitas media pengangkut (knapsack)

\section{Algoritma Greedy}

Algoritma greedy digunakan untuk memperoleh penyelesaian dari suatu permasalahan optimasi. Suatu permasalahan dengan $n$ masukkan data dilakukan secara bertahap. Pertama dilakukan pemilihan solusi dari ketiga strategi kemudian himpunan solusi dari ketiga strategi tersebut akan diperoleh solusi yang paling optimal, Hasan [3]. Menurut Brassard [2], algoritma greedy adalah algoritma untuk menyelesaikan permasalahan secara bertahap. Terdapat beberapa strategi Greedy yang dapat digunakan untuk memilih objek yang akan dimasukkan ke dalam $M$ antara lain:

a. Greedy by profit

Knapsack diisi dengan objek yang mempunyai keuntungan terbesar. Strategi ini mencoba memaksimumkan keuntungan dengan memilih objek yang paling menguntungkan terlebih dahulu. Pertama kali dilakukan adalah mengurutkan secara menurun objek-objek berdasarkan profitnya. Kemudian objek- objek yang dapat ditampung oleh knapsack diambil satu persatu sampai knapsack penuh atau sudah tidak ada objek lagi yang bisa dimasukkan.

b. Greedy by weight

Knapsack diisi dengan objek yang mempunyai berat paling ringan. Strategi ini mencoba memaksimumkan keuntungan dengan memasukkan sebanyak mungkin objek ke dalam knapsack. Pertama kali dilakukan adalah mengurutkan secara menaik objek-objek berdasarkan beratya. Kemudian objek- objek yang dapat ditampung oleh knapsack diambil satu persatu sampai knapsack atau sudah tidak ada objek lagi yang bisa dimasukkan.

c. Greedy by density

Knapsack diisi dengan objek yang mempunyai $p_{i} / w_{i}$ terbesar dimana $p$ adalah keuntungan dan $w$ adalah berat barang. Strategi ini mencoba memaksimumkan keuntungan dengan memilih objek yang mempunyai keuntungan per unit (density) berat terbesar. Pertama kali yang dilakukan adalah mencari nilai profit per weight density daritiap-tiap objek. Kemudian objek-objek diurutkan berdasarkan density terbesar. Kemudian objek-objek yang dapat ditampung oleh knapsack diambil satu persatu sampai knapsack penuh atau sudah tidak ada objek lagi yang bisa dimasukkan. 


\section{Hasil dan Pembahasan}

\section{Data Pengangkutan Barang Toko Surya Muda Pekanbaru}

Data yang diambil dari Toko Surya Muda Pekanbaru berupa data berat barang perunit, banyaknya barang yang dibeli, harga beli barang dan harga jual barang. Data tersebut dapat dilihat pada Tabel 1 sebagai berikut:

Tabel 1 Daftar Barang yang diangkut

\begin{tabular}{|c|l|c|c|r|r|}
\hline No. & \multicolumn{1}{|c|}{ Nama Barang ke- $\tilde{i}}$. & $\begin{array}{c}\text { Berat Barang } \\
\text { Perunit (Kg) }\end{array}$ & $\begin{array}{c}\text { Banyak } \\
\text { Barang (unit) }\end{array}$ & Harga Beli (Rp) & Harga Jual (Rp) \\
\hline 1 & GULA & 50 & 1 & 570.000 & 650.000 \\
\hline 2 & TEPUNG TERIGU & 25 & 1 & 195.000 & 212.500 \\
\hline 3 & GARAM & 50 & 1 & 575.000 & 690.000 \\
\hline$\vdots$ & $\vdots$ & $\vdots$ & $\vdots$ & $\vdots$ & $\vdots$ \\
\hline 38 & $1 / 2$ LUSIN TEH PUCUK & 4,5 & 2 & 144.000 & 192.000 \\
\hline 39 & 1 LUSIN M-150 & 2 & 1 & 39.600 & 60.000 \\
\hline 40 & PLASTIK KACA & $1 / 4$ & 20 & 150.000 & 180.000 \\
\hline
\end{tabular}

Sumber: Toko Surya Muda Pekanbaru (2019)

Berdasarkan Tabel 1, untuk mempermudah penyelesaian permasalahan integer knapsack maka tabel dapat disederhanakan dengan memisalkan dengan simbol, seperti berikut ini:

Nama barang ke-1 disimbolkan dengan angka 1;

Nama barang ke-2 disimbolkan dengan angka 2;

Nama barang ke-3 disimbolkan dengan angka 3;

$\vdots$

Nama barang ke-40 disimbolkan dengan angka 40.

\section{Mengidentifikasikan Data Berdasarkan Berat dan Keuntungan}

Identifikasikan data untuk memperoleh berat $w_{i}$ dan keuntungan $p_{i}$. $w_{i}$ diperoleh dari mengalikan bobot berat barang perunit dengan banyak barang, dan $p_{i}$ diperoleh dari selisih harga jual dan harga beli, hasil identifikasi dapat dilihat pada Tabel 2 sebagai berikut:

Tabel 2. Daftar Identifikasi dari Tabel 1

\begin{tabular}{|c|c|c|r|}
\hline No. & Barang ke-i & $w_{i}^{-}(\mathrm{Kg})$ & $p_{i}(\mathrm{Rp})$ \\
\hline 1 & 1 & 50 & 80.000 \\
\hline 2 & 2 & 25 & 17.500 \\
\hline 3 & 3 & 50 & 115.000 \\
\hline$\vdots$ & $\vdots$ & $\vdots$ & $\vdots$ \\
\hline 38 & 38 & 9 & 48.000 \\
\hline 39 & 39 & 2 & 20.400 \\
\hline 40 & 40 & 5 & 30.000 \\
\hline
\end{tabular}

\section{Penyusunan Model Permasalahan Integer Knapsack}

Berdasarkan Tabel 2, dapat disusun model permasalahan integer knapsack. Permasalahan integer knapsack terdapat beberapa variabel yang akan digunakan, fungsi kendala dan fungsi tujuan. Adapun variabel yang akan digunakan, fungsi tujuan dan fungsi kendala adalah sebagai berikut:

a. Menentukan variabel yang akan digunakan

$p_{i}$ : Keuntungan barang ke- $i$ keseluruhan

$w_{i}$ : Berat barang ke- $i$ keseluruhan

$x_{i}$ : Barang ke- $i$ yang dipilih (1 jika dipilih, 0 jika tidak dipilih)

$M$ : Kapasitas media pengangkut (knapsack) 
b. Menentukan fungsi tujuan

$$
\text { Maksimum } \quad Z=\sum_{i=1}^{n} p_{i} x_{i}
$$

c. Menentukan fungsi kendala

$$
w_{i} x_{i} \leq M
$$

Berdasarkan model permasalahan integer knapsack, sehingga diperoleh formulasi untuk permasalahan integer knapsack adalah sebagai berikut:

FungsiTujuan:

Maksimum

$$
\begin{aligned}
Z= & 80.000 x_{1}+17.500 x_{2}+115.000 x_{3}+24.000 x_{4}+15.000 x_{5}+15.000 x_{6}+10.000 x_{7}+20.000 x_{8} \\
& +20.000 x_{9}+5.000 x_{10}+5.000 x_{11}+20.000 x_{12}+24.000 x_{13}+20.000 x_{14}+12.000 x_{15}+20.000 x_{16} \\
& +2.000 x_{17}+49.000 x_{18}+6.000 x_{19}+20.000 x_{20}+18.000 x_{21}+105.000 x_{22}+42.500 x_{23}+50.000 x_{24} \\
& +148.000 x_{25}+8.000 x_{26}+4.000 x_{27}+12.000 x_{28}+3.000 x_{29}+6.000 x_{30}+9.000 x_{31} \\
& +24.000 x_{32}+24.000 x_{33}+12.000 x_{34}+24.000 x_{35}+12.000 x_{36}+12.000 x_{37}+48.000 x_{38} \\
& +20.400 x_{39}+30.000 x_{40}
\end{aligned}
$$

Dengan fungsi kendala :

$$
\begin{aligned}
& 50 x_{1}+25 x_{2}+50 x_{3}+12 x_{4}+10 x_{5}+10 x_{6}+10 x_{7}+10 x_{8}+10 x_{9}+5 x_{10}+5 x_{11}+5 x_{12}+12 x_{13}+5 x_{14} \\
& +4 x_{15}+5 x_{16}+2 x_{17}+28 x_{18}+6 x_{19}+10 x_{20}+18 x_{21}+95 x_{22}+55 x_{23}+55 x_{24}+28 x_{25}+9 x_{26}+4 x_{27} \\
& +7 x_{28}+10 x_{29}+17 x_{30}+3 x_{31}+7 x_{32}+9 x_{33}+6 x_{34}+9 x_{35}+6 x_{36}+4 x_{37}+9 x_{38}+2 x_{39}+5 x_{40} \leq 500 \\
& x_{1}, x_{2}, x_{3}, x_{4}, x_{5}, x_{6}, x_{7}, x_{8}, x_{9}, x_{10}, x_{11} x_{12}, x_{13}, x_{14}, x_{15}, x_{16}, x_{17}, x_{18}, x_{19}, x_{20}, x_{21}, x_{22} \\
& , x_{23}, x_{24}, x_{25}, x_{26}, x_{27}, x_{28}, x_{29}, x_{30}, x_{31}, x_{32}, x_{33}, x_{34}, x_{35}, x_{36}, x_{37}, x_{38}, x_{39}, x_{40} \in\{0,1\}
\end{aligned}
$$

\section{Pengaplikasian Algoritma Greedy}

Langkah 1: Barang-barang yang terdapat pada Tabel 2 diurutkan berdasarkan profit $\left(p_{i}\right)$ terbesar, selanjutnya dengan mengurutkan daftar barang-barang yang ada pada Tabel 2 sehingga diperoleh tabel sebagai berikut:

Tabel 3. Urutan Daftar Barang Berdasarkan Profit Terbesar

\begin{tabular}{|c|c|c|r|}
\hline No & Barang ke-i. & $W_{i}(\mathrm{Kg})$ & $p_{\mathrm{i}}(\mathrm{Rp})$ \\
\hline 1 & 25 & 28 & 148.000 \\
\hline 2 & 3 & 50 & 115.000 \\
\hline 3 & 22 & 95 & 105.000 \\
\hline$\vdots$ & $\vdots$ & $\vdots$ & $\vdots$ \\
\hline 38 & 27 & 4 & 4.000 \\
\hline 39 & 29 & 10 & 3.000 \\
\hline 40 & 17 & 2 & 2.000 \\
\hline
\end{tabular}

Langkah 2: Mengambil satu persatu barang yang terdapat pada Tabel 3 yang dapat diangkut tanpa melebihi kapasitas knapsack. Diketahui bahwa kapasitas maksimum pengangkut sebesar $500 \mathrm{~kg}$ dengan menggunakan strategi Greedy by profit maka diperoleh tabel pengangkutan barang ke dalam permasalahan knapsack sebagai berikut:

Tabel 4. Pengangkutan Barang ke dalam Permasalahan Knapsack Menggunakan Strategi Greedy by Profit

\begin{tabular}{|c|c|c|c|c|c|}
\hline No & Barang ke- $\tilde{i}$ & $W_{i}(\mathrm{Kg})$ & $p_{i}(\mathrm{Rp})$ & Status & $x_{\hat{i}}$ \\
\hline 1 & 25 & 28 & 148.000 & Diambil & 1 \\
\hline 2 & 3 & 50 & 115.000 & Diambil & 1 \\
\hline 3 & 22 & 95 & 105.000 & Diambil & 1 \\
\hline$\vdots$ & $\vdots$ & $\vdots$ & $\vdots$ & $\vdots$ & $\vdots$ \\
\hline 38 & 27 & 4 & 4.000 & Tidak & 0 \\
\hline
\end{tabular}




\begin{tabular}{|l|l|l|l|l|l|}
\hline 39 & 29 & 10 & 3.000 & Tidak & 0 \\
\hline 40 & 17 & 2 & 2.000 & Tidak & 0 \\
\hline
\end{tabular}

Berdasarkan Tabel 4 diperoleh

$x_{1}=1, x_{2}=0, x_{3}=1, x_{4}=1, x_{5}=1, x_{6}=0, x_{7}=0, x_{8}=1, x_{9}=1, x_{10}=0, x_{11}=0$, $x_{12}=1, x_{13}=1, x_{14}=1, x_{15}=0, x_{16}=1, x_{17}=0, x_{18}=1, x_{19}=0, x_{20}=1, x_{21}=1$, $x_{22}=1, x_{23}=1, x_{24}=1, x_{25}=1, x_{26}=0, x_{27}=0, x_{28}=0, x_{29}=0, x_{30}=0, x_{31}=0$, $x_{32}=1, x_{33}=1, x_{34}=0, x_{35}=1, x_{36}=0, x_{37}=0, x_{38}=1, x_{39}=1, x_{40}=1$

Solusi optimal permasalahan ini adalah $X=\{1,0,1,1,1,0,0,1,1,0,0,1,1,1,0,1,0,1,0,1,1,1,1,1,1,0,0,0,0,0$, $0,1,1,0,1,0,0,1,1,1$.

yang artinya barang ke-1, 3, 4, 5, 8, 9, 12, 13, 14,16, 18, 20, 21, 22, 23, 24, 25, 32, 33, 35, 38, 39 dan 40 diambil dengan total keuntungan maksimum sebesar Rp 960.900,- .

a. Menggunakan strategi Greedy by Weight dalam menyelesaikan permasalahan knapsack

Langkah 1: Barang-barang yang ada pada Tabel 2 diurutkan berdasarkan weightnya atau berat terkecil. Selanjutnya dengan mengurutkan daftar barang-barang yang ada pada Tabel 2 sehingga diperoleh tabel sebagai berikut:

Tabel 5. Urutan Daftar Barang Berdasarkan Berat Terkecil

\begin{tabular}{|c|c|c|r|}
\hline No. & Barang ke- $\boldsymbol{i}$ & $\boldsymbol{w}_{\boldsymbol{i}}(\mathrm{Kg})$ & $\boldsymbol{p}_{\boldsymbol{i}}(\mathrm{Rp})$ \\
\hline 1 & 17 & 2 & 2.000 \\
\hline 2 & 39 & 2 & 20.400 \\
\hline 3 & 31 & 3 & 9.000 \\
\hline$\vdots$ & $\vdots$ & $\vdots$ & $\vdots$ \\
\hline 38 & 23 & 55 & 42.500 \\
\hline 39 & 24 & 55 & 50.000 \\
\hline 40 & 22 & 95 & 105.000 \\
\hline
\end{tabular}

Langkah 2: Mengambil satu persatu barang yang terdapat pada Tabel 5 yang dapat diangkut tanpa melebihi kapasias knapsack. Diketahui bahwa kapasitas maksimum pengangkut sebesar $500 \mathrm{~kg}$ dengan menggunakan strategi Greedy by Weight maka diperoleh tabel pengangkutan barang ke dalam permasalahan knapsack sebagai berikut:

Tabel 6. Pengangkutan Barang ke dalam Permasalahan Knapsack Menggunakan Strategi Greedy by Weight

\begin{tabular}{|c|c|c|r|c|c|}
\hline No & Barangke- $\boldsymbol{i}$ & $\boldsymbol{w}_{\boldsymbol{i}}(\mathrm{Kg})$ & $\boldsymbol{p}_{\boldsymbol{i}}(\mathrm{Rp})$ & Status & $\boldsymbol{x}_{\tilde{\boldsymbol{i}}}$ \\
\hline 1 & 17 & 2 & 2.000 & Diambil & 1 \\
\hline 2 & 39 & 2 & 20.400 & Diambil & 1 \\
\hline 3 & 31 & 3 & 9.000 & Diambil & 1 \\
\hline$\vdots$ & $\vdots$ & $\vdots$ & $\vdots$ & $\vdots$ & $\vdots$ \\
\hline 38 & 23 & 55 & 42.500 & Diambil & 1 \\
\hline 39 & 24 & 55 & 50.000 & Tidak & 0 \\
\hline 40 & 22 & 95 & 105.000 & Tidak & 0 \\
\hline
\end{tabular}

Berdasarkan Tabel 6 diperoleh

$x_{1}=1, x_{2}=1, x_{3}=1, x_{4}=1, x_{5}=1, x_{6}=1, x_{7}=1, x_{8}=1, x_{9}=1, x_{10}=1, x_{11}=1$, $x_{12}=1, x_{13}=1, x_{14}=1, x_{15}=1, x_{16}=1, x_{17}=1, x_{18}=1, x_{19}=1, x_{20}=1, x_{21}=1$, $x_{22}=0, x_{23}=1, x_{24}=0, x_{25}=1, x_{26}=1, x_{27}=1, x_{28}=1, x_{29}=1, x_{30}=1, x_{31}=1$, $x_{32}=1, x_{33}=1, x_{34}=1, x_{35}=1, x_{36}=1, x_{37}=1, x_{38}=1, x_{39}=1, x_{40}=1$

Solusi optimal permasalahan ini adalah $X=\{1,1,1,1,1,1,1,1,1,1,1,1,1,1,1,1,1,1,1,1,1,0,1,0,1,1,1,1,1,1$, $1,1,1,1,1,1,1,1,1,1\}$ 
yang artinya barang ke-1, 2, 3, 4, 5, 6, 7, 8, 9, 10, 11, 12, 13, 14, 15, 16, 17, 18,19, 20, 21, 23, 25, $26,27,28,29,30,31,32,33,34,35,36,37,38,39$ dan 40 diambil dengan total keuntungan maksimum sebesar Rp 956.400,- .

b. Menggunakan strategi Greedy by Density dalam menyelesaikan permasalahan knapsack Langkah 1: Mencari nilai rasio $p_{i} / w_{i}$ dari setiap barang, dengan mencari nilai rasio perberat atau biasa disebut density di setiap barang. Sehingga didapatkan tabel sebagai berikut:

Tabel 7. Nilai Density dari Tiap Barang

\begin{tabular}{|c|c|c|r|r|}
\hline No. & Barang ke- $\boldsymbol{i}$ & $\boldsymbol{w}_{\boldsymbol{i}}(\mathrm{Kg})$ & $\boldsymbol{p}_{\boldsymbol{i}}(\mathrm{Rp})$ & \multicolumn{1}{c|}{$\boldsymbol{p}_{\boldsymbol{i}} / \boldsymbol{w}_{\boldsymbol{i}}$} \\
\hline 1 & 1 & 50 & 80.000 & $1.600,000$ \\
\hline 2 & 2 & 25 & 17.500 & 700,000 \\
\hline 3 & 3 & 50 & 115.000 & $2.300,000$ \\
\hline$\vdots$ & $\vdots$ & $\vdots$ & $\vdots$ & $\vdots$ \\
\hline 38 & 38 & 9 & 48.000 & $5.333,333$ \\
\hline 39 & 39 & 2 & 20.400 & $10.200,000$ \\
\hline 40 & 40 & 5 & 30.000 & $6.000,000$ \\
\hline
\end{tabular}

Langkah 2: Barang-barang yang terdapat pada Tabel 7 diurutkan berdasarkan nilai Densitynya terbesar. Selanjutnya dengan mengurutkan barang-barang pada Tabel 7 sehingga diperoleh tabel sebagai berikut:

Tabel 8. Urutan Barang-barang dari Density Terbesar

\begin{tabular}{|c|c|c|r|r|}
\hline No. & Barangke- $\boldsymbol{i}$ & $\boldsymbol{w}_{\boldsymbol{i}}(\mathrm{Kg})$ & $\boldsymbol{p}_{\boldsymbol{i}}(\mathrm{Rp})$ & $\boldsymbol{p}_{\boldsymbol{i}} / \boldsymbol{w}_{\boldsymbol{i}}$ \\
\hline 1 & 39 & 2 & 20.400 & $10.200,000$ \\
\hline 2 & 40 & 5 & 30.000 & $6.000,000$ \\
\hline 3 & 38 & 9 & 48.000 & $5.333,333$ \\
\hline$\vdots$ & $\vdots$ & $\vdots$ & $\vdots$ & $\vdots$ \\
\hline 38 & 2 & 25 & 6.000 & 700,000 \\
\hline 39 & 30 & 17 & 3.000 & 352,941 \\
\hline 40 & 29 & 10 & & \\
\hline
\end{tabular}

Langkah 3: Mengambil satu persatu barang yang terdapat pada Tabel 8 yang dapat diangkut tanpa melebihi kapasitas knapsack. Diketahui bahwa kapasitas maksimum pengangkut sebesar $500 \mathrm{~kg}$ dengan menggunakan strategi Greedy by Density maka diperoleh tabel pengangkutan barang ke dalam permasalahan knapsack sebagai berikut:

Tabel 9. Pengangkutan Barang ke dalam Permasalahan Knapsack Menggunakan Strategi Greedy by Density

\begin{tabular}{|c|c|c|c|c|c|c|}
\hline No. & Barang ke- $\boldsymbol{i}$ & $\boldsymbol{w}_{\boldsymbol{i}}(\mathrm{Kg})$ & $\boldsymbol{p}_{\boldsymbol{i}}(\mathrm{Rp})$ & $\boldsymbol{p}_{\boldsymbol{i}} / \boldsymbol{w}_{\boldsymbol{i}}$ & Status & $\boldsymbol{x}_{\tilde{i}}$ \\
\hline 1 & 39 & 2 & 20.400 & $10.200,000$ & Diambil & 1 \\
\hline 2 & 40 & 5 & 30.000 & $6.000,000$ & Diambil & 1 \\
\hline 3 & 38 & 9 & 48.000 & $5.333,333$ & Diambil & 1 \\
\hline$\vdots$ & $\vdots$ & $\vdots$ & $\vdots$ & $\vdots$ & $\vdots$ & $\vdots$ \\
\hline 38 & 2 & 25 & 17.500 & 700,000 & Diambil & 1 \\
\hline 39 & 30 & 17 & 6.000 & 352,941 & Tidak & 0 \\
\hline 40 & 29 & 10 & 3.000 & 300,000 & Tidak & 0 \\
\hline
\end{tabular}

Berdasarkan Tabel 9 diperoleh

$x_{1}=1, x_{2}=1, x_{3}=1, x_{4}=1, x_{5}=1, x_{6}=1, x_{7}=1, x_{8}=1, x_{9}=1, x_{10}=1, x_{11}=1$,

$x_{12}=1, x_{13}=1, x_{14}=1, x_{15}=1, x_{16}=1, x_{17}=1, x_{18}=1, x_{19}=1, x_{20}=1, x_{21}=1$,

$x_{22}=1, x_{23}=0, x_{24}=0, x_{25}=1, x_{26}=1, x_{27}=1, x_{28}=1, x_{29}=0, x_{30}=0, x_{31}=1$,

$x_{32}=1, x_{33}=1, x_{34}=1, x_{35}=1, x_{36}=1, x_{37}=1, x_{38}=1, x_{39}=1, x_{40}=1$

Solusi optimal permasalahan ini adalah 
Berdasarkan dari ketiga strategi Greedy didapatkan hasil bahwa barang yang akan diangkut oleh Toko Surya Muda Pekanbaru adalah gula, tepung terigu, garam, dolpin, beras topikoki, beras anak daro, interco, plastik royal 15 , plastik royal 19 , plastik royal 24 , kantong HD PE, masako, tepung beras, kopi bubuk sepeda, sambal abc, minyak rose brand, ajinamoto, minyak curah, boom, kantong plastik P.E, gas, aqua besar, aqua sedang, ale-ale, torpedo, o'caffe, kratindeng, kecap bango, Fanta, mizone, sprite, pocari, lasegar, teh pucuk, M-150 dan plastik kaca. Sedangkan barang yang tidak diangkut adalah muraqua, sms, x-teh dan teh gelas. Sehingga keuntungan maksimum yang diperoleh oleh Toko Surya Muda Pekanbaru sebesar Rp 1.009.900,- .

\section{Kesimpulan}

Berdasarkan hasil pembahasan, pengangkutan barang untuk permasalahan knapsack pada Toko Surya Muda Pekanbaru dengan menggunakan algoritma greedy mendapatkan keuntungan maksimum. Hasil menggunakan algoritma greedy dengan tiga strategi yaitu Greedy by Profit diperoleh keuntungan maksimum sebesar Rp 960.900, Greedy by Weight diperoleh keuntungan maksimum sebesar Rp 956.400,Greedy by Density diperoleh keuntungan maksimum sebesar Rp 1.009.900. Berdasarkan ketiga strategi tersebut, penyelesaian Greedy by Density menghasilkan keuntungan yang lebih besar bagi Toko Surya Muda Pekanbaru.

\section{Daftar Pustaka}

[1] Ambarwari, A., dan Yanto, N. W., "Penerapan Algoritma Greedy pada Permasalahan Knapsack untuk Optimasi Pengangkutan Peti Kemas", Research Gate, 2016.

[2] Brassard, G., " Fundamentals of Algorithms", New Jersey: Prentice Hall, 1996.

[3] Hasan. M., "Implemetasi Algoritma Greedy dalam Menyelesaikan Kasus Knapsack Problem", Makassar: Jurusan Matematika Sains dan Teknologi UIN Alaudinn Makassar, 2016.

[4] Paryati, "Optimasi Strategi Algoritma Greedy untuk Menyelesaikan Permasalahan Knapsack 01”, In Seminar Nasional Informatika (SEMNASIF), 2015.

[5] Pratiwi, A., dkk. "Implementasi Algoritma Branch and Bound pada 0-1 Knapsack Problem untuk Mengoptimalkan Muatan Barang”. Jurnal Matematika Unnes, 2014.

[6] Setemen, K., "Implementasi Algoritma Genetik pada Knapsack Problem untuk Optimasi Pemilihan Buah Kemasan Kotak", Seminar Nasional Aplikasi Teknologi Informasi, Yogyakarta, 2010.

[7] Zulhidayati, I., "Aplikasi Algoritma Greedy dan Program Dinamis (Dynamic Programming) pada Permainan Greddy Spiders", Bandung: Universitas Pendidikan Indonesia, 2013. 